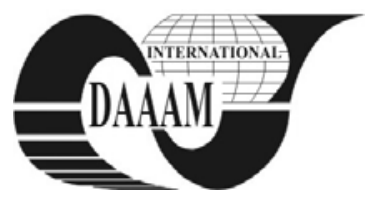

\title{
THE TRAINING OPTIMIZATION OF ENGINEERS FOR MANUFACTURING SYSTEMS
}

\author{
GEORGESCU, L[uminita] E[lena]; DOBRESCU, T[iberiu] G[abriel] \& ILIESCU, M[ihaiela]
}

\begin{abstract}
Currently, many countries are concerned of implementing the labour employment policies, based on the criteria of competitiveness, development and social cohesion. The processes of human resource training are directly responsible for the output quality of any process. Persons involved in the processes of training and improvement can become more flexible and more efficient. This study enabled, by statistical processing of data, the evaluation of skills specific to the graduates in higher technical education, Quality Engineering (QE), IMST Faculty, Polytechnic University of Bucharest
\end{abstract}

Key words: development, skills, optimization, competition, evolution

\section{INTRODUCTION}

Economic performance of an organization depends on the quality of human resources, which in turn is conditional on the level of training and improvement of employees. Training and improvement are intertwined, sometimes difficult to determine whether certain activities are training or refresher courses.

Professional training is really efficient when the objectives of the program are consistent with the labour market requirements, where the universities have a leading role.

Optimizing human resources training for production systems can be considered a topical issue that meet both the interests of society, trainers, employees and employers interested in the judicious and efficient use of human resources.

\section{TRAINING IN THE CONTEXT OF GLOBALIZATION}

The documentation has shown that more countries are concerned to develop a strong working relationship between the education and the job requirements.

To have sustainable economic growth, it is required a skilled and competitive workforce (fig.1 after Martory, 2005).

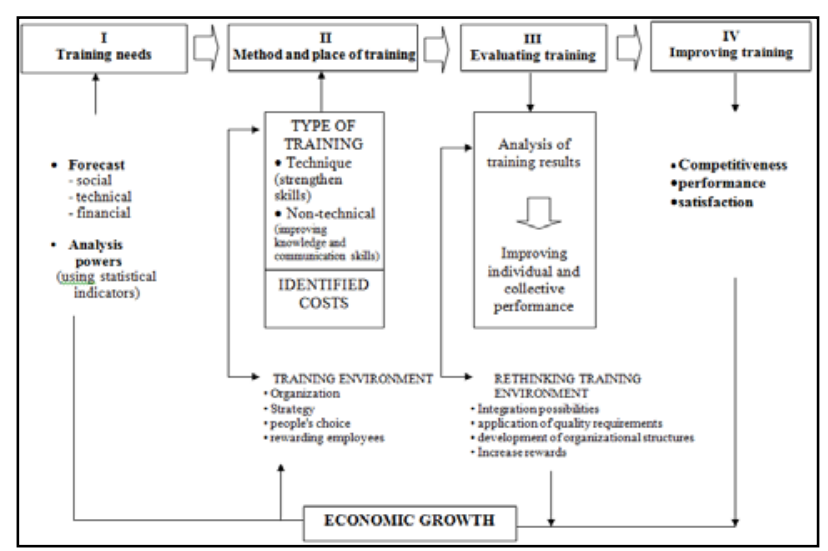

Fig. 1. Measures to optimize the investment in training
This process (fig.1) must overcome the following limitations: the high level of competitiveness, limited training time and budget.

The current trend in Europe is the adoption and implementation of occupational standards. These standards describe the reference items as for-achieving the quality performance in an activity and serve as a guide for developing training programs and for evaluating specific competencies in activities that carry out work force.

The premise of present research was the need of training and developing the skills that engineers do need for getting in motion the mechanism of market economy and of social development.

\section{EVALUATION OF TRAINING ENGINEERS}

The appropriate qualification for the specialization QE Quality Engineering, formed during their university studies, can be expressed by the following professional and transverse competencies (Georgescu, 2009):

A. Cross competencies (general)

A1.Role competencies

A1.1. Interpersonal and managerial communication

A1.2. Team work abilities

A2. Personal and professional development competencies

A2.1. General Development in the technical field

A2.2. Proficiency of the basic technical preparation

B. Professional competencies:

B1. Cognitive competencies:

B1.1.Knowing, understanding and using the quality engineering theories

B1.2. Development, implementation and proficiency of the quality engineering methods

B2. Functional-actionable competencies:

B2.1. Writing and analyzing the quality system documents

B2.2.Elaboration of the environmental management documents B2.3.Utilization and maintenance of quality management informatics systems

B2.4. Utilization of the proper quality inspection methods, techniques and instruments

B2.5. Interpretation of the documents from the quality management's point of view

B2.6. Knowing and applying the quality assurance standards

A large number of disciplines of study, with a certain importance, calculated proportionally to the number of hours allocated per semester discipline contribute to the development of each chosen competence.

Because it was not studied the group which represents all students that have studied in the considered education unit, the specialization Quality Engineering, the research was done using a random and representative sample with the number of observations equal to 15 .

Based on numerical data analysis, and aided by applied statistics, there can be formed deductions and conclusions on the expressed characteristics. 


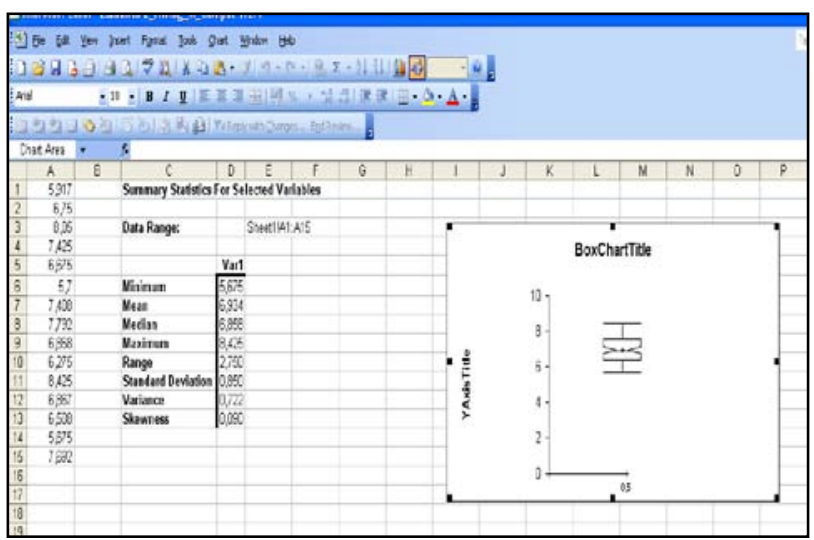

Fig. 2. Results of the analysis competence A2.1 with the Box Sampler software (Georgescu, 2010)

\begin{tabular}{|c|l|c|c|}
\hline stem & \multicolumn{1}{|c|}{ leaf } & $\mathrm{f}$ & $\mathrm{p}$ \\
\hline 5 & $675,700,917$ & 3 & 0,200 \\
\hline 6 & $\begin{array}{l}275,508,675,750, \\
858,867\end{array}$ & 6 & 0,400 \\
\hline 7 & $408,425,692,792$ & 4 & 0,267 \\
\hline 8 & 050,425 & 2 & 0,133 \\
\hline cod: $5 \quad 917 \rightarrow 5,917$ & $\sum f=15$ & $\sum p=1$ \\
\hline
\end{tabular}

Tab. 1. Diagram” Stem and Leaf”

The quality of the studied data is very important and it depends on the way they were obtained (Iliescu, 2009).

By processing obtained data with the specialized software Box Sampler, for A2.1 "General technical development", the following results were obtained (fig. 2):

- extreme values: 5,675 and 8,425

- variation field: 2,750

- average values: $\bar{x}=6,934$

- variance: $\sigma^{2}=0,722 \mathrm{~s}^{2}$

- standard deviation: $\sigma=0,850 \mathrm{~s}$

We can say that if $\bar{X}$ is the average selection for a given selection of $n$ size, derived from a population with normal distribution and known variance $\sigma^{2}$, then, with a probability of $100 \cdot(1-\alpha) \%$, the real value of the average $\mu$ is within the confidence interval, given by the expression:

$$
\left[\bar{X}-z_{\frac{\alpha}{2}} \cdot \frac{\sigma}{\sqrt{n}} ; \bar{x}+z_{\frac{\alpha}{2}} \cdot \frac{\sigma}{\sqrt{n}}\right] \Leftrightarrow\left[\bar{x}-z_{\frac{\alpha}{2}} \cdot s ; \bar{x}+z_{\frac{\alpha}{2}} \cdot s\right]
$$

ie:

$$
\left(\bar{x}-z_{\frac{\alpha}{2}} \cdot \frac{\sigma}{\sqrt{n}} \leq \mu \leq \bar{x}+z_{\frac{\alpha}{2}} \cdot \frac{\sigma}{\sqrt{n}}\right) \Leftrightarrow\left(\bar{x}-z_{\frac{\alpha}{2}} \cdot s \leq \mu \leq \bar{x}+z_{\frac{\alpha}{2}} \cdot s\right)
$$

Where: $Z_{\frac{\alpha}{2}}$ represents the value of $z$, which limits the percentage of $100 \cdot \frac{\alpha}{2} \%$ the standard normal distribution.

By plotting chart "'Steam and Leaf", the distribution of the studied values (frequency and relative frequency), on the considered ranges, is underlined.

Frequency histogram plotted by using SPC KISS software is highlighted by fig.3.

On the studied sample, the distribution of the values is not similar with the normal one. Concerning interest data, a large share in the range of marks from the interval $[6,7)$ does not represent a convenient situation.

Analyzing the competence A2.1 "General technical development”, presented in fig.3, it appears that only six of the subjects received more than mark 7.

Advance study of some basic disciplines, can be the cause of obtaining lower results at the mentioned competence. Another cause can be the shift from the specific training system for secondary education to higher education, which some young people realise and become harder aware.

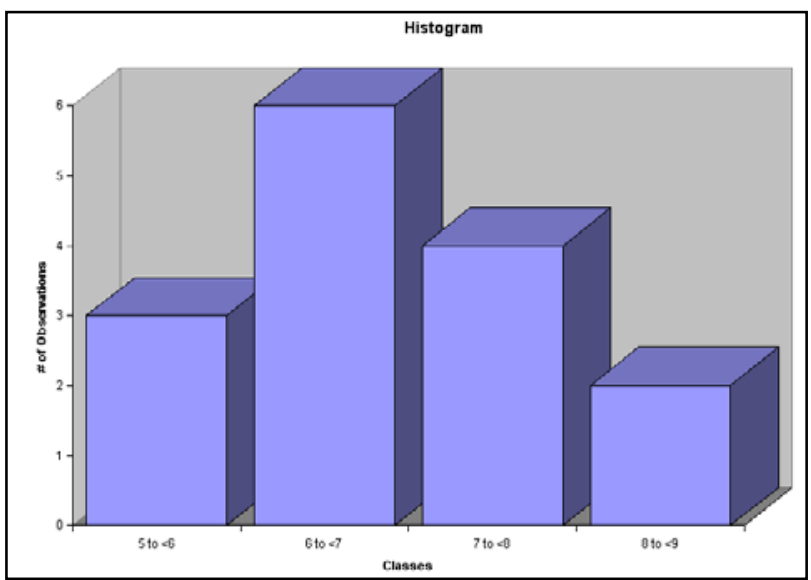

Fig. 3. Frequency histogram for the competencies A2.1

\section{CONCLUSION}

The novelty of the study is to establish a methodology to quantify the satisfaction level of required skills for technical education specializations.

Who is addressed this methodology to?

Having clearly defined powers for technical specializations in faculty and the share of the disciplines in the development competencies, with this methodology, trainers, economic agents interested in certain skills of graduates and not least the students can learn, after each semester or year of study, the level reached in each competency.

The benefits of applying this methodology:

- Permanent monitoring of student creates the possibility to recover (partially or totally) the disciplines where poor results were obtained;

- "orders" teachers to update and modernize the courses to form the skills required for engineers on the labour market;

- enables rapid selection and recruiting of future graduates

Teaching should always be consistent with the stage reached by the science and the directions of evolution. Educational plans and programs must be continuously upgraded to the European labour market requirements.

\section{REFERENCES}

Georgescu, L. (2009) Cercetări privind optimizarea formării resurselor umane pentru sistemele industriale, Teza de doctorat, Bucuresti

Georgescu, L. (2010) Optimizarea formării resurselor umane pentru sistemele industriale, POLITEHNICA, ISBN 978606-515-120-8, Bucuresti

Iliescu, M. (2009) Statistica aplicata, MAN-DELY, ISBN 9736-7689-08-9, Bucuresti

Martory, B. \& Crozet, D.(2005). GESTION DES RESSOURCES HUMAIES - Pilotage social et performances, DUNOD, ISBN 2-10-049445-7

*** (2003) http//www.see-educoop.net- European Community Commission, Accessed on: 2008-04-13

*** (2007) http://www.humanscience.wikia.com - Employment trends in the 21st, Accessed on: 2008-11-05 